\title{
Aspectos epidemiológicos dos acidentes ofídicos ocorridos no Estado de Roraima, Brasil, entre 1992 e 1998
}

\author{
Epidemiological characteristics of snakebites \\ in the State of Roraima, Brazil, 1992-1998
}

\footnotetext{
1 Museu Integrado de Roraima.

Av. Brigadeiro Eduardo Gomes s/no, Parque Anauá, Boa Vista, RR 69305-000, Brasil.
}

\begin{abstract}
Theauthor presentsa study on snakebites in 8 counties in the State of Roraima, Brazil, from 1992 to 1998. A total of 309 recorded snakebites were described and analyzed by place, fatality, sex, time of day, date, month, and age distribution. Most of the reported cases involved genus Bothrops (81.8\%). The most frequently invol ved counties were Al to Al egre (49.0\%), São Luiz do Anauá (14.9\%), and Normandia (10.3\%). Cases occurred most frequently in the months of March and July, and especially during the daytime (74.8\%).

Key words Snake Bites; Snakes; Epidemiology
\end{abstract}

Resumo O presentetrabal ho apresenta um estudo relativo a acidentes ofídicos ocorridos em oito municípios do Estado de Roraima entre 1992 e 1998. Trezentas e nove (309) fichas de regi stro de aci dentes por serpentes peçonhentas foram descritas por locali dade e comentadas segundo óbi tos, sexo, período do dia, época do ano e distribuição etária. A maioria dos casos notificados resul tou de aci dentes com serpentes do gênero Bothrops (81,8\%). As localidades de maior incidência foram os muni cípi os de Alto Al egre (49,0\%), São Luiz do Anauá (14,9\%) e Normandia (10,3\%). A maior ocorrência de casos foi observada nos meses de março ejulho, assim como o índice mais el evado de acidente teve lugar no período di urno (74,8\%).

Palavras-chave Mordeduras de Cobras; Cobras; Epi demi ologia 
Introdução

Os casos de envenenamento por acidentes ofídicos ocorridos em todo o Brasil são produzidos por serpentes dos gêneros Bothrops (jararaca), Crotalus (cascavel), Lachesis (surucucu) e Micrurus (corais verdadeiras). Em Roraima ocorre a presença dos quatro gêneros assinalados para o restante do país. Esses ofídios vêm causando acidentes freqüentes à população da região, formada principalmente por trabalhadores rurais. Em geral, tais casos têm lugar nas proximidades das habitações e/ ou áreas cultivadas, portanto, fora do ambiente natural das serpentes.

A despeito disso, estudos relacionados à fauna regional de ofídios são escassos, destacando-se, até o presente momento, os trabaIhos de Cunha et al. (1980), de Nascimento (1995) e de O'sea (1998). Em virtude da escassez de semelhantes informações, não é possível obter dados que proporcionem entendimento mais pleno do atual quadro de acidentes ofídicos ocorridos nessa região setentrional do Brasil. No entanto, este constitui um importante problema de saúde pública para a Amazônia e, em particular, para Roraima. Tomando em conta essa lacuna, foram reunidas as poucas informações disponíveis nos órgãos públicos locais para tecer comentários relativos ao quadro que ora se forma para o Estado de Roraima.

\section{Material e método}

No presente trabalho foram avaliados todos os casos de acidentes por serpentes peçonhentas notificados em oito municípios do Estado de Roraima no período compreendido entre 1992 e 1998. O número desses casos perfez um total de 309 fichas individuais, a partir das quais foram analisadas as seguintes variáveis: espécie de serpente, localidade do acidente, período diário, época do ano, óbito, sexo e idade da vítima. As fichas foram preenchidas quando do atendimento do acidentado no centro de saúde mais próximo do local onde ocorreu o acidente, em geral, na sede do município. Observe-se que, usualmente, as vítimas são atendidas sem a necessidade de transferência para outro centro maior, o que é feito apenas em caso de extrema gravidade.

Após o tratamento do acidentado, as fichas são enviadas para uma central de diagnóstico da Secretaria Estadual da Saúde, em Boa Vista, onde são arquivadas. A partir delas foram obtidas as informações utilizadas no presente trabalho. Entretanto, nem todas as fichas avalia- das registravam informações completas. Do total, as que declararam dados relativos às localidades foram somente 194; a respeito da espécie de serpente, 187 , quanto ao período do dia no momento do acidente, 139; acerca do sexo do paciente, 205; e, por fim, no que concerne à faixa etária do acidentado, 197. Além disso, não há registros disponíveis de casos anteriores a 1992.

\section{Resultados}

Em Roraima, a serpente que ocasionou o maior número de acidentes entre 1992 e 1998 foi a do gênero Bothrops (jararaca), que aparece em $81,8 \%$ ( $n=153$ ) dos casos registrados. Em seguida encontra-se Crotal us (cascavel) em 13,4\% dos casos ( $n=25$ ), Lachesis (surucucu) em 4,3\% $(n=8)$ e Micrurus (coral) em 0,5\% $(n=1)$.

As localidades com maior número de acidentes foram os municípios de Alto Alegre $(n=$ 95) com $49,0 \%$ dos casos, e de São Luiz do Anauá ( $n=29$ ) com 14,9\%. O Município de Mucajaí foi a localidade que registrou o menor número de casos para o período analisado $(n=1)$, correspondendo a $0,5 \%$ do total de registros. Os demais municípios apresentaram os seguintes números: Boa Vista, 17 casos (8,8\%); Bonfim, 3 (1,5\%); Caracaraí, 14 (7,2\%); Normandia, 20 (10,3\%); e São João da Baliza, 15 casos (7,7\%).

Julho foi o mês de maior incidência de acidentes ofídicos, quando foram notificados $16,1 \%$ dos casos. Os meses de março e maio apresentaram picos secundários com $11,8 \%$ e $11,3 \%$, respectivamente (Tabela 1 ).

Tabela 1

Acidentes ofídicos em Roraima, de 1992 a 1998.

\begin{tabular}{lrr}
\hline Meses & Casos & $\%$ \\
\hline J aneiro & 13 & 7,0 \\
Fevereiro & 10 & 5,4 \\
Março & 22 & 11,8 \\
Abril & 15 & 8,1 \\
Maio & 21 & 11,3 \\
J unho & 14 & 7,5 \\
Julho & 30 & 16,1 \\
Agosto & 14 & 7,5 \\
Setembro & 10 & 5,4 \\
Outubro & 7 & 3,8 \\
Novembro & 14 & 7,5 \\
Dezembro & 16 & 8,6 \\
Total & 186 & \\
\hline
\end{tabular}


O horário de maior incidência de acidentes situou-se no período diurno com $74,8 \%$ ( $n=104$ ) dos casos arrolados entre 1992 e 1998. No período noturno foram registrados 35 casos (25,2\%).

Dos casos avaliados, $75,6 \%$ ocorreram com indivíduos do sexo masculino $(n=155)$, enquanto que os do sexo feminino registraram percentual de $24,4 \%(n=50)$.

As faixas etárias em que houve o maior número de acidentados foram as de 15-30 e 31-45 anos, representando respectivamente $26,0 \%$ e $26,4 \%$ dos casos. Observou-se que o número de acidentes decresce de modo considerável na faixa etária acima dos 56 anos, apresentando índice de apenas 3,0\% (Tabela 2).

De todos os casos ocorridos entre $1992 \mathrm{e}$ 1998, foram registrados óbitos em 3,9\% $(n=12)$.

\section{Discussão}

As serpentes peçonhentas são encontradas tanto em áreas abertas quanto nas de mata. Em Roraima, a forma assinalada para áreas abertas é a subespécie Crotalus durissus ruruima, descrita por Hoge (1965) como proveniente do Monte Roraima, situado nos limites entre Brasil, Venezuela e Guiana. Os exemplares para estudo foram coletados em território venezuelano (Cunha et al., 1980). Como nenhum estudo mais detalhado a respeito dessa subespécie foi efetuado em Roraima, as informações quanto a sua taxonomia ainda são bastante confusas. Contudo, Vanzolini (1986) esclarece que o gênero Crotalus provavelmente entrou na América do Sul através da América Central durante o Plioceno. É verossímil que sua dispersão tenha acontecido em períodos secos, encontrando-se hoje tipicamente distribuído nas formações abertas.
Em Roraima, essa serpente é a segunda maior causadora de acidentes ofídicos, ou seja, cerca de 13,4\% dos casos registrados entre 1992 e 1998.

Nas áreas de mata ocorrem as espécies Bothrops bilineatus e Bothrops atrox. Esta última tem sido bastante estudada na Amazônia, principalmente com vistas à taxonomia, em virtude tanto de sua extrema variação quanto pela importância que apresenta para a ecologia das regiões onde é abundante. Em Roraima, onde foi responsável por $81,8 \%$ dos acidentes registrados na região, a $B$. atrox é comum em razão de seu alto grau de adaptabilidade a diferentes tipos de ambientes.

Outra forma peçonhenta de área florestada é a Lachesi s muta, presente em Roraima e no resto da Amazônia, onde se encontra bem caracterizada na diagnose e nos comentários de Cunha \& Nascimento $(1975,1978,1982)$ e Cunha et al. (1985). A despeito de sua ampla distribuição geográfica, a espécie também está claramente definida, conforme atesta Chippaux (1986) em estudos realizados na Guiana Francesa. Esta serpente é pouco freqüente nas áreas em que habita, ocasionando raros acidentes.

O gênero Micrurus é encontrado em toda região Neotropical. No Brasil existem mais de 30 espécies com algumas subespécies (Cunha $\&$ Nascimento, 1978), das quais - segundo Celso Morato de Carvalho, em comunicado pessoal - pelo menos cinco espécies ocorrem nas áreas de mata de Roraima: Micrurus surinamensis, Micrurus lemniscatus, Micrurus hemprichi i, Micrurus averyi e Mi crurus karlschmiditi. Entretanto, esse grupo não está ainda perfeitamente estudado na Amazônia, em particular quanto aos aspectos taxonômicos, ecológicos e de distribuição geográfica (Cunha \& Nascimento, 1993).

Freqüência de acidentes ofídicos por faixa etária: 1992 a 1998, Roraima.

\begin{tabular}{lrrrrrrrrrr}
\hline Idade (anos) & Casos & $\%$ & 1992 & 1993 & 1994 & 1995 & 1996 & 1997 & 1998 \\
\hline$<15$ & 49 & 24,9 & 3 & 4 & 4 & 13 & 6 & 12 & 7 \\
$15-30$ & 71 & 36,0 & 7 & 14 & 7 & 6 & 9 & 16 & 12 \\
$31-45$ & 52 & 26,4 & 8 & 13 & 4 & 8 & 9 & 7 & 3 \\
$46-55$ & 19 & 9,6 & 2 & 6 & 1 & 1 & 4 & 4 & 1 \\
$>56$ & 6 & 3,0 & 0 & 1 & 0 & 1 & 2 & 1 & 1 \\
Total & 197 & 100 & 20 & 38 & 16 & 29 & 30 & 40 & 24 \\
\hline
\end{tabular}


No que diz respeito ao veneno das corais, poucos estudos têm sido feitos no Brasil. Felizmente, casos de acidentes causados por essas serpentes não são comuns em Roraima. Explica-se isso pelo fato de que as espécies são pouco freqüentes e vivem em ambientes nos quais as pessoas nem sempre as encontram. Além do mais, a dentição das Micrurus (proteróglifa) apresenta disposição diferente daquela encontrada nos gêneros Crotal us, Bothrops e Lachesis (dentição solenóglifa). Sua boca não se abre elasticamente e as presas que inoculam peçonha são pequenas, situando-se na parte mediana do maxilar. Estas serpentes de colorido marcante mostram certas semelhanças com outras espécies do grupo não peçonhento (Colubridae). Em decorrência disso, é comum o povo não distinguir algumas espécies de serpentes não peçonhentas das que o são realmente, como, por exemplo, as serpentes dos gêneros Pseudoboa e Erythrolamprus, que costumam ser confundidas com as corais verdadeiras, embora sejam formas não peçonhentas. Outra espécie que se presta a engano é a Leptodeira annulata, uma tímida e inofensiva serpente, cujo nome popular é jararaca. As pessoas a confundem com a verdadeira jararaca (Bothrops), ainda que sejam diferentes uma da outra (Nascimento, 1995).

Do total de casos registrados (309), o Município de Alto Alegre teve o maior índice de acidentes ofídicos, $49 \%$ dos casos. Fisionomicamente, Alto Alegre apresenta dois tipos de formações vegetais: floresta e áreas abertas (lavrado). Em tais ambientes estão presentes todos os gêneros de serpentes peçonhentas indicados para Roraima. Nessa região - em que são freqüentes os casos de acidentes ofídicos de acordo com comunicado pessoal dos técnicos da Secretaria Estadual da Saúde -, ocorreu a maioria dos poucos casos de acidentes ofídicos cometidos por L. muta e Micrurus. Contudo, é importante destacar que ali está situada a Terra Indígena Yanomami, na qual foi registrada a maioria dos acidentes $(74,0 \%)$ para aquele município em função, talvez, do maior contato dos índios com as serpentes na mata.

São Luiz do Anauá e São João da Baliza (áreas de mata) e Normandia (áreas abertas), apresentaram índices de 14,9\%, 7,7\% e 10,3\%, respectivamente, do total de casos registrados. Nas localidades de São Luiz do Anauá e São João da Baliza, todos os casos notificados foram ocasionados por serpentes do gênero Bothrops. Em Normandia, a maioria dos casos foi com C. durissus ruruima. Da mesma forma, os municípios de Boa Vista e Bonfim - localidades também de áreas abertas - apresenta- ram baixa freqüência de casos registrados: $8,8 \%$ e $1,5 \%$, respectivamente.

Os Municípios de Caracaraí e Mucajaí (áreas abertas e mata) tiveram também baixo índice de casos registrados: 7,2\% e 0,5\%, respectivamente. Em suas formações vegetais, essas localidades apresentam diferentes tipos de ambientes, os quais propiciam a presença de todos os gêneros peçonhentos assinalados para Roraima. Porém, com exceção de um único caso de picada por L. muta no Município de Caracaraí, todos os acidentes ofídicos observados para essas regiões foram com serpentes do gênero Bothrops.

Em relação à sazonalidade, observou-se que os acidentes ocorreram em todas as épocas do ano e, na maioria, com trabalhadores rurais (78,0\%). Entretanto houve aumento de acidentes nos meses de julho, março e maio, em decorrência, provavelmente, de maior atividade do homem no campo. O mês de julho coincide com o pico das chuvas na região, período que o lavrador está em plena atividade agrícola (plantio, capina e colheita). Março e maio, são os meses que apresentam baixa pluviosidade (período seco), época que propicia a limpeza de pastos eáreas para cultivo. Essas situações oferecem maior possibilidade de contato das pessoas com a serpente, uma vez que o acidente ocorre sempre que o homem quebra a distância de fuga do animal, ou seja, a distância em que ela se sente segura de qualquer agressão. Observou-se também que a maioria dos acidentes registrados aconteceu, em especial, nos meses de maior temperatura (março/abril) e pluviosidade (julho), coincidindo com maior atividade das serpentes nesses períodos, tendo sido a principal causadora da maioria dos acidentes registrados a B. atrox. Segundo Cunha \& Nascimento (1978), esta é a espécie peçonhenta que mais comumente freqüenta áreas cultivadas na Amazônia. No que se refere ao período diário dos acidentes, observou-se que a maioria (74,8\%) ocorreu durante o dia, coincidindo com os horários de maior atividade do homem e maior incidência de sol, ou seja, das 10:00 às 15:00 horas. De modo geral, as serpentes peçonhentas apresentam hábitos noturno. Porém, essa predominância de casos durante o dia pode estar relacionada também com a possível atividade das serpentes nesses horários de pico. Em determinadas situações as serpentes podem variar seus hábitos, como, por exemplo, em função de maior disponibilidade de alimentos durante o dia (Cunha \& Nascimento, 1978).

Quanto ao sexo dos acidentados, 205 casos de acidentes ofídicos foram analisados. A mai- 
oria (75,6\%) afetou indivíduos do sexo masculino, a mesma situação observada por Martinez et al. (1995) para o Vale do Ribeira, região sudeste do Estado de São Paulo, sugerindo que esta observação possa ter sido feita em razão da maior atividade do homem fora do lar. Dos acidentes com pessoas do sexo feminino, observou-se que todos os casos registrados ocorreram fora do ambiente doméstico. Contudo, não existem estudos complementares relacionados à incidência de acidentes ofídicos por sexo em outras regiões do país para melhor comparação com os dados do presente trabalho. A faixa etária das pessoas com maior ocorrência de acidentes está entre 15 e 45 anos ( $62,4 \%$ dos casos notificados). Com os indivíduos menores de 15 anos, observou-se ligeira elevação do índice nos anos de 1995 e 1997. A maioria desses acidentes ocorreu entre estudantes da zona rural e em horários que coincidiam sempre com os de início e término das aulas. Isto sugere que essa faixa etária está mais suscetível a sofrer acidentes ofídicos em tais condições do que em outras ocupações rotineiramente desenvolvidas por essa classe de indivíduos. Acima de 46 anos, o número de casos registrados diminuiu em razão, provavelmente, da baixa atividade das pessoas nesta faixa etária. A distribuição de idade observada aqui é próxima das distribuições relatadas para outras regiões do país (Resende et al., 1989; Ribeiro et al., 1993; Martinez et al., 1995).

\section{Agradecimentos}

À equipe da Coordenação de Zoonoses e Animais Peçonhentos da Secretaria Estadual de Saúde de Roraima pela cessão das fichas de notificação de acidentes ofídicos. Ao Distrito Sanitário Yanomami (DSY/FNS) por ter cedido informações a respeito dos acidentes ofídicos ocorridos nas áreas indígenas.
O óbito é fator ausente nos acidentes ocorridos nas localidades com melhor infra-estrutura de saúde e estradas vicinais. Isso permite brevidade no atendimento médico, evitandose, dessa maneira, o óbito e/ ou a remoção do acidentado para atendimento em localidades mais distantes, o que demandaria mais tempo, piorando consequentemente as condições de saúde do acidentado. Este fato acontece em áreas isoladas, como, por exemplo, nas áreas indígenas dos Yanomami e Yekuana, onde ocorreram todos os casos de óbitos avaliados pelo presente trabalho (3,9\% do total de casos registrados). Segundo informações pessoais da equipe de saúde do Distrito Sanitário Yanomami (DSY)/ Fundação Nacional de Saúde (FNS), é possível que o número de óbitos nessas localidades seja ainda maior em virtude da ausência de informações.

Foi impossível quantificar melhor o número de casos, uma vez que não possuíam todas as informações completas mais de $50 \%$ dos casos analisados, ainda que não se possa atribuir tal fato à ausência de compromisso do pessoal de saúde. Para obtenção de diagnóstico mais preciso, as instituições de saúde pública deverão envidar esforço ainda maior no tocante ao controle de ações ofidiológicas. É importante que se procure desenvolver procedimentos de rotina capazes de contribuir para a ampliação dos conhecimentos de fenômenos que caracterizam o complexo quadro epidemiológico dos acidentes ofídicos (Dalmora et al., 1992).

\section{Referências}

CHIPPAU X, J. P., 1986. Les Serpentes de la Guyane Française. Paris: Editions de Lörstom.

CUNHA, O. R. \& NASCIMENTO, F. P., 1975. Ofídios da Amazônia. VII. As serpentes peçonhentas do gênero Bothrops (jararaca) e Lachesis (surucucu) da região leste do Pará. (Ophidia: Elapidae e Viperidae). Boletim do Museu Paraense Emílio Goel di (Zoologia), 20:1-42.

CUNHA, O. R. \& NASCIMENTO, F. P., 1978. Ofídios da Amazônia. X. As cobras da região leste do Pará. Museu Paraense Emílio Goeldi. Publicações Avulsas, 1:7-166

CUNHA, O. R. \& NASCIMENTO, F. P., 1982. Ofídios da Amazônia. XIV. As espécies de Micrurus, Bothrops, Lachesise Crotalus do sul do Pará e oeste do Maranhão, incluindo áreas do cerrado deste Estado (Ophidia: Elapidae e Viperidae). Boletim do Museu Paraense Emílio Goeldi (Zoologia), 112:158. 
CUNHA, O. R. \& NASCIMENTO, F. P., 1993. Ofídios da Amazônia. X. As cobras da região leste do Pará. Boletim do Museu Paraense Emílio Goeldi (Zoologia), 9:1-191.

CUNHA, O. R.; NASCIMENTO, F. P. \& HOGE, A. R., 1980. Ofídios da Amazônia. XI. Ofídios de Roraima e notas sobre Erythrolamprus bauperthuisi i (Linnaeus, 1752). Boletim do Museu Paraense Emílio Goeldi (Zoologia), 120:1-21.

CUNHA, O. R.; NASCIMENTO, F. P. \& ÁVILA-PIRES, T. C. S., 1985. Os répteis da área de Carajás, Pará, Brasil (Testudines e Squamata). Bol etim do Museu Paraense Emílio Goeldi (Publicações Avulsas), 40:9-85.

DALMORA, S. L.; VACCARI, S. F.; SAM PEDRO, A. M. \& PEREIRA, J. E. S., 1992. Dosagem biológica do antiveneno botrópico. Memórias do Instituto Butan$\tan , 54: 21-30$.

HOGE, A. R., 1965. Preliminary account on Neotropical Crotalinae (Serpentes: Viperidae). Memórias do Instituto Butantan, 32:109-84.

MARTINEZ, E. G.; VILANOVA, M. C. T.; JORGE, M.T. \& RIBEIRO, L. A., 1995. Aspectos epidemiológicos do acidente ofídico no Vale do Ribeira, São Paulo, 1985 a 1989. Cadernos de Saúde Pública, 11:511515.

NASCIMENTO, S. P., 1995. Notas sobre Leptodeira annulata de Roraima I. Variações no número de escamas em populações de mata e lavrado (Serpentes: Colubridae). Boletim do Museu Integrado de Roraima, 3:20-35.

O'SEA, M. T., 1998. The Reptilian Herpetofauna of the Ilha de Maracá. In: Maracá: The Biodiversity and Environment of an Amazonian Rainforest (W. Millikem \& J. A. Ratter, eds.), pp. 231-261, Londres: John Wiley \& Sons.

RESENDE, C. C.; ARAÚJO, F. A. A. \& SALLENAVE, R. N. U. R., 1989. Análise Epidemiológica dos Aci dentes Ofídicos. Brasília: Ministério da Saúde.

RIBEIRO, L. A.; PIRES-DE-CAMPOS, V. A. F.; ALBU QUERQUE, M. J. \& TAKAOKA, N. Y., 1993. Acidente ofídico no estado de São Paulo. Revista da Associação Médica Brasileira, 39:4-7.

VANZOLINI, P. E., 1986. Paleoclimas e Especiação em Animais da América do Sul Tropical. São Paulo: Associação Brasileira de Estudos do Quaternário. 